\begin{tabular}{|c|c|c|c|}
\hline $\begin{array}{l}\text { Yuya Ando, MD } \\
\text { Department of Internal Medicine, } \\
\text { Division of Gastroenterology, Self- } \\
\text { Defense Forces Central Hospital, Tokyo, } \\
\text { Japan; Department of Family Medicine, } \\
\text { Graduate School of Medical and Dental } \\
\text { Sciences, Tokyo Medical and Dental } \\
\text { University, Tokyo, Japan }\end{array}$ & $\begin{array}{l}\text { Sachiko Ono, MPH, PhD } \\
\text { Department of Eat-loss Medicine, } \\
\text { Graduate School of Medicine, } \\
\text { The University of Tokyo, Tokyo, Japan }\end{array}$ & $\begin{array}{l}\text { Yosuke Ono, MD, PhD } \\
\text { Department of General Medicine, } \\
\text { National Defense Medical College, } \\
\text { Saitama, Japan }\end{array}$ & $\begin{array}{l}\text { Yoshinori Miura, MD, PhD } \\
\text { Department of Dermatology, Self-Defense } \\
\text { Forces Central Hospital, Tokyo, Japan }\end{array}$ \\
\hline
\end{tabular}

\title{
Hypertrichosis and topical corticosteroid use
}

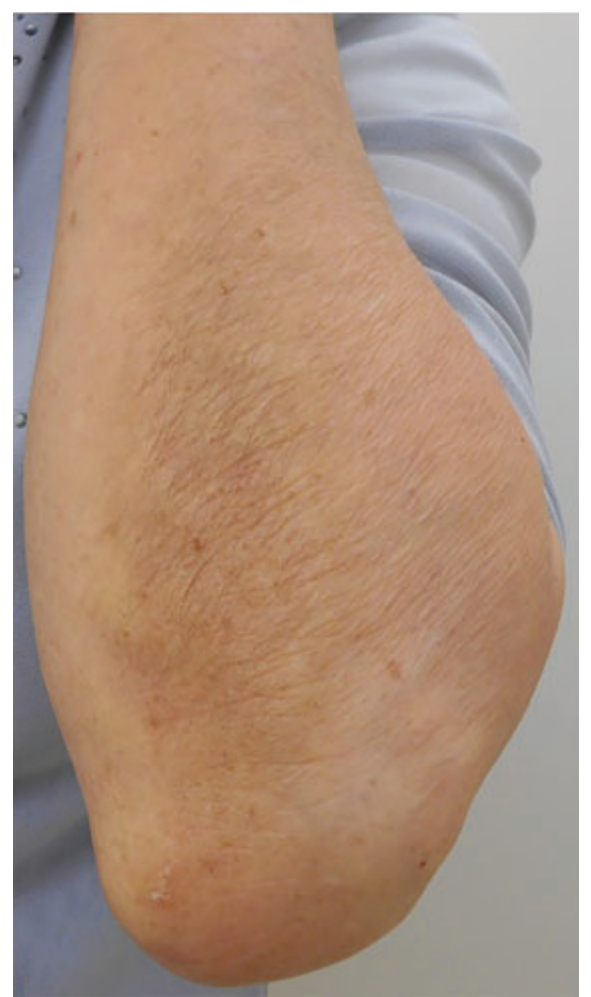

Figure 1. Thick hair growth on the patient's left forearm.

\footnotetext{
a 8o-year-old woman with mild dementia presented to our clinic with a chief complaint of recent hair growth on her left forearm. On examination, the hair was thick and restricted to the ulnar side of the left forearm (Figure 1). The left forearm also had striae atrophicae (Figure 2).

The patient's medical history revealed that 2 years earlier she had been prescribed the topical steroid betamethasone butyrate propionate for treatment of xerotic dermatitis, which doi:10.3949/ccjm.89a.21048
}

had subsided within a short period. However, she had continued to apply the corticosteroid to her left arm for more than 2 years after the dermatitis had subsided, and she was still using it at the time of presentation.

The hair on the left forearm was significantly longer and denser than on the right forearm. The abnormal hair growth occurred where the topical steroid was applied. Because these findings were unilateral, we excluded conditions such as hirsutism, ovarian hyperthecosis, androgen-secreting ovarian and adrenal tumors, and Cushing disease, and we diagnosed her with hypertrichosis caused by long-term use of steroid ointment.
Hypertrichosis is an adverse effect of topical corticosteroids 


\section{DIFFERENTIAL DIAGNOSIS OF HYPERTRICHOSIS}

Hypertrichosis is an abnormal amount of hair growth that can be distributed anywhere on the body. Regarding the differential diagnosis, it is important to separate hypertrichosis from hirsutism, which is defined as abnormal hair growth on the skin of females in androgeninfluenced areas that are considered characteristic for hair growth in males, such as the mustache region. ${ }^{1}$

Race and ethnicity also affect the differential diagnosis of hypertrichosis. For instance, regardless of the serum androgen concentration in women of reproductive age, East Asian and Native American women usually have less body hair, while women of Mediterranean ethnicities have many more body hair.

Furthermore, hypertrichosis is not a malignant condition, whereas hirsutism implies an underlying hormonal disorder because it is most frequently caused by polycystic ovary syndrome. ${ }^{2}$ Idiopathic hirsutism is the appearance of hirsutism in females without abnormal serum androgen concentrations, menstrual disorders, or other clinical disorders. ${ }^{3}$

In addition, endocrine disorders associated with excessive androgen production such as congenital adrenal hyperplasia, androgen-secreting tumors, and ovarian hyperthecosis can cause hirsutism. Drugs such as danazol and any type of androgen therapy are also associated with excessive hair growth. Hypertrichosis can also be caused by topical minoxidil for alopecia areata and prostaglandin analog therapy. ${ }^{4}$

\section{TOPICAL CORTICOSTEROIDS AND HYPERTRICHOSIS}

Although topical corticosteroids are considered safer than systemic corticosteroids, they can cause local cutaneous and systemic adverse effects. The most common local side effects are atrophy, striae, rosacea, perioral dermatitis, acne, and purpura, while hypertrichosis, pigment alteration, delayed wound-healing, and exacerbation of skin infection are less common. ${ }^{5}$ Widespread use of high-potency topical corticosteroids or chronic topical corticosteroid use can cause suppression of the hypothalamicpituitary axis. ${ }^{5}$ Less frequent but important systemic effects of these drugs are hyperglycemia, glaucoma, and adrenal insufficiency. ${ }^{6}$

\section{CASE CONCLUSION}

Our patient had been using betamethasone butyrate propionate ointment, which is available in Japan but not in the United States. It is a dermatologic corticosteroid categorized as a potent (group III) drug by the World Health Organization Anatomical Therapeutic Chemical classification system, ${ }^{7}$ which classifies topical steroids from group I (weak) to group IV (very potent).

We considered that the patient's localized use of this topical corticosteroid for more than 2 years led to the hypertrichosis and striae atrophicae on her left forearm. We tapered the dose of topical corticosteroid, and consequently, the amount of hair decreased considerably.

The key to successful topical corticosteroid use is accurate prescription and good communication with patients. Clinicians should caution patients that excessive use and overuse of topical corticosteroids can lead to hypertrichosis as a cutaneous adverse effect.

\section{DISCLOSURES}

The authors report no relevant financial relationships which, in the context of their contributions, could be perceived as a potential conflict of interest.

\section{REFERENCES}

1. Carmina E, Koyama T, Chang L, Stanczyk FZ, Lobo RA. Does ethnicity influence the prevalence of adrenal hyperandrogenism and insulin resistance in polycystic ovary syndrome? Am J Obstet Gynecol 1992; 167(6):1807-1812. doi:10.1016/0002-9378(92)91779-a

2. Carmina E, Rosato F, Jannì A, Rizzo M, Longo RA. Extensive clinical ex perience: relative prevalence of different androgen excess disorders in 950 women referred because of clinical hyperandrogenism. J Clin Endocrinol Metab 2006; 91(1):2-6. doi:10.1210/jc.2005-1457

3. Azziz R, Carmina E, Sawaya ME. Idiopathic hirsutism. Endocr Rev 2000; 21(4):347-362. doi:10.1210/edrv.21.4.0401

4. Alm A, Grierson I, Shields MB. Side effects associated with prostaglandin analog therapy. Surv Ophthalmol 2008; 53[Suppl1]:S93-S105. doi:10.1016/j.survophthal.2008.08.004

5. Coondoo A, Phiske M, Verma S, Lahiri K. Side-effects of topical steroids: a long overdue revisit. Indian Dermatol Online J 2014; 5(4):416-425. doi:10.4103/2229-5178.142483

6. Hengge UR, Ruzicka T, Schwartz RA, Cork MJ. Adverse effects of topical glucocorticosteroids. J Am Acad Dermatol 2006; 54(1):1-18. doi:10.1016/j.jaad.2005.01.010

7. World Health Organization. WHO Collaborating Centre for Drug Statistics Methodology. ATC/DDD index. https://www.whocc.no/ atc_ddd_index/?code=D07AC01. Accessed January 20, 2022.

Address: Yosuke Ono, Department of General Medicine, National Defense Medical College, 3-2 Namiki, Tokorozawa, Saitama 359-8513, Japan; onoyousuke1979@yahoo.co.jp 